\title{
NEST-SITE LIMITATION IN COFFEE AGROECOSYSTEMS: ARTIFICIAL NESTS MAINTAIN DIVERSITY OF ARBOREAL ANTS
}

\author{
Stacy M. Philpott ${ }^{1}$ And Paul F. Foster \\ Department of Ecology and Evolutionary Biology, $830 \mathrm{~N}$. University Avenue, University of Michigan, \\ Ann Arbor, Michigan 48109-1048 USA
}

\begin{abstract}
Nest sites are a limiting resource for arboreal twig-nesting ants, and nest sites may be increasingly limited with habitat modification. One such habitat modification is the conversion of traditional coffee farms, where coffee is cultivated under a dense, diverse shade canopy, to more intensive production systems with reduced canopy cover and lower diversity, height, and density of shade trees. As a result of such management intensification, ant diversity declines. We ask here if: (1) nest sites are a limiting resource for arboreal twig-nesting ants in coffee farms, especially in intensively managed systems and (2) nest-site limitation is a mechanism causing loss of ant diversity with coffee management intensification. During 2000-2003, we investigated occupancy, species richness, and species composition of arboreal twig-nesting ants using natural (hollow coffee twig) and artificial (bamboo stem) nests in farms either with high or low diversity and density of shade trees. In both high- and low-shade sites ants occupied a majority $(>55 \%)$ of natural nests and occupied some $(>15 \%)$ artificial nests, and significantly more artificial nests were occupied in low-shade sites. In both high- and low-shade sites, ant richness was higher in artificial than in natural nests. More species occupied natural nests in low-shade sites, and more species occupied artificial nests in high-shade sites. Furthermore, species composition differed between nest types, with more ant species found more often or only in artificial nests. These results indicate that, although ants are not strongly nest-site limited in coffee agroecosystems, nest limitation increases somewhat with increasing management intensification. Reductions in numbers of nest sites may be a mechanism causing ant diversity loss with coffee management intensification. Interestingly, because relatively fewer species colonized artificial nests in the low-shade site, ants may be recruitment limited in the lowshade sites, possibly maintaining low ant richness in these sites.
\end{abstract}

Key words: biodiversity loss; biological control; Chiapas, Mexico; coffee agroecosystem; nestsite limitation; recruitment limitation; twig-nesting ants.

\section{INTRODUCTION}

Ants are diverse and abundant in tropical habitats, sometimes making up $>85 \%$ of arthropod biomass in forest canopies (Hölldobler and Wilson 1990, Davidson 1997, Davidson et al. 2003). Ants use many nest substrates including soil, leaf litter, tree stumps, plant domatia, and dry or fallen twigs (Hölldobler and Wilson 1990) and are frequently assumed to be nest-site limited. Although litter twig-nesting ants may be limited by either size or availability of twig nests (Herbers 1986, Kaspari 1996, Foitzik and Heinze 1998, Fonseca 1999), relatively less is known about nest limitation in arboreal twig-nesters (Carroll 1979). Nest-space limitation may mean that only larger ants can occupy larger nests (i.e., those with greater volume or larger entrances); (Fonseca 1999), and smaller ants dominate smaller nests (Carroll 1979, but see Byrne 1994). Evidence for

Manuscript received 28 September 2004; accepted 8 November 2004; Final version received 21 January 2005. Corresponding Editor: J. A. Logan.

${ }^{1}$ Present address: Smithsonian Migratory Bird Center, National Zoological Park, 3001 Connecticut Avenue NW, Washington, D.C. 20008 USA. E-mail: philpotts@ si.edu nest-site limitation is suggested when ants: (1) occupy high proportions of available nests (Torres 1984, Byrne 1994), (2) occupy artificial nests implying natural nests are not abundant enough (Herbers 1986, Perfecto and Vandermeer 1994, Andresen 2003), (3) compete for nest sites (Davidson et al. 1989, Way and Bolton 1997, Stanton et al. 2002, Solano et al. 2003), and (4) aggressively take over nests occupied by other ants (Brian 1952, Yamaguchi 1992, Hasegawa 1993, Vasconcelos 1993, Cerda and Retana 1998). Although distributions of some species are not determined by competitive interactions (Fernandez-Escudero and Tinaut 1999, Ribas and Schoereder 2002) and nest colonization by some ants is not affected by ant presence on the same plants (Byrne 1994), nest-site limitation is arguably the strongest factor by which the number and size of arboreal twig-nesting ant colonies are limited (Carroll 1979), a factor which may be exacerbated by habitat modifications.

Converting natural ecosystems to agroecosystems or intensifying agroecosystems may increase nest-site limitation resulting in lower ant abundance and diversity. Normally, as natural ecosystems are converted to 
agroecosystems (or as agroecosystems are intensified), trees are eliminated or pruned. Coffee was traditionally cultivated under a diverse, dense shade canopy, but recent production is characterized by increased management intensity - namely removing or reducing the density and diversity of shade trees, shade tree pruning, and intensive use of agrochemicals and fertilizers (Moguel and Toledo 1999). Coffee intensification is also associated with lower ant diversity (Nestel and Dickschen 1990, Perfecto and Snelling 1995, Perfecto et al. 1996, 1997, Roberts et al. 2000, Perfecto and Vandermeer 2002, Armbrecht and Perfecto 2003). Arboreal twig-nesting ants use dry hollow twigs in trees and other vegetation as nests. As shade trees are pruned or removed, the total number of available nest sites decreases, and arboreal ants may be increasingly forced into the coffee layer where ant nest-site limitation should increase. Furthermore, as the number of available nest sites declines, ant diversity and abundance may decline because inferior competitors may not persist in intensively managed farms. Thus one mechanism underlying the loss of ant diversity may be increased nest-site limitation due to a decrease in the number of available nest sites.

We investigated if arboreal twig-nesting ants in coffee agroecosystems are nest-site limited by measuring ant use of natural and artificial nests. We specifically tested if (1) nest sites are a limiting resource for twignesting ants, (2) nest sites become more limiting with coffee management intensification, and (3) nest-site limitation is a mechanism for loss of ant diversity with coffee intensification. We predicted that (1) ants would occupy most natural and artificial nests sites and (2) a higher proportion of natural and artificial nests would be occupied in more intensively managed (low-shade) sites because of a lower availability of nest sites in low-shade sites. Furthermore, it is possible that some ant species (inferior competitors) will have been excluded from natural nests due to competition such that natural nests are primarily occupied by a few species of competitive dominants. We thus expected that increasing nest availability would increase ant diversity so that (1) ant richness would be greater in artificial nests (i.e., after less time for competitive exclusion), and (2) ant species composition would differ between nest types where more species occur in a higher proportion of artificial nests than natural nests (i.e., natural nests are dominated by a few species).

\section{Methods}

We carried out our nest studies in two coffee farms in the Soconusco region of Chiapas, Mexico, Finca Irlanda $\left(15^{\circ} 11^{\prime} \mathrm{N}, 92^{\circ} 20^{\prime} \mathrm{W}\right)$ and Finca Belen $\left(15^{\circ} 15^{\prime}\right.$ $\left.\mathrm{N}, 92^{\circ} 23^{\prime} \mathrm{W}\right)$. Both farms are organically managed plantations, $\sim 300$ ha in size, located between 900 and $1150 \mathrm{~m}$ elevation, receive $\sim 4500 \mathrm{~mm} \mathrm{rain} / \mathrm{yr}$, and maintain $\sim 1200-2500$ coffee plants/ha. Each farm has one area of relatively high shade tree diversity, height, density, and percent cover (Belen Rustic [BR] and Irlanda Restoration [IR]) and another area of low shade tree diversity, height, density, and percent cover (Belen Production [BP] and Irlanda Production [IP]) (Mas and Dietsch 2003, Perfecto et al. 2003). We thus examined natural and artificial nest densities and occupation in two high- and two low-shade sites.

We first examined abundance and ant occupation of available twig nests defined as naturally occurring hollow coffee twigs. On 13 dates, approximately every two months from July 2000 to June 2001 and again from December 2001 to March 2003, we broke off all dry twigs from 10 previously unsampled coffee bushes in each site for a total of 560 coffee plants (101 in BR, 140 in IR, 120 in BP, and 199 in IP) and 9323 individual twigs. For each coffee bush sampled, we counted total numbers of dry twigs, hollow twigs, ant-occupied twigs, and recorded the identity of each ant species found. We considered a nest to be occupied if it contained alates (males or queens), brood, and/ or workers. We calculated proportion of available nests (hollow twigs) occupied by ants for each shade type (high and low) and sampling date.

To study artificial nest use by twig-nesting ants, we attached hollow bamboo twigs in coffee bushes with twist ties and later checked artificial nests for ant occupants. Every two months between July 2000 and June 2001 and December 2001 to January 2003, we placed five bamboo twigs $(10-20 \mathrm{~cm}$ long with $3-10 \mathrm{~mm}$ diameter openings at one end) on each of 20 coffee bushes, flush with branches, 0.5-2.0 m above ground. We used bamboo of these varying sizes to best approximate the size and size variation of nests in hollow coffee twigs. After two months, for a total of 14 harvests, we removed and opened all nests and recorded the number of nests recovered, number occupied, and the identity of the species occupying the nest. Voucher specimens of all ants that could not be identified to species will be deposited in collections at the Smithsonian Institution. Some nests $(7.6 \%)$ fell or were lost during the two-month period, but we harvested a total of 4605 artificial nests (1122 in BR, 1213 in IR, 1094 in BP, and 1176 in IP). Again, all nests with alates, brood, and/or workers were included as occupied. We calculated occupancy as the total number of occupied artificial nests per total nests recovered, standardized as nest occupancy per 60 days. For both natural and artificial nests, we compared total available nests and proportion of occupied nests using ANOVAs. We used untransformed proportions and log-transformed numbers of available nests to meet conditions of normality.

To compare ant richness in artificial and natural nests in both high- and low-shade sites, we generated species accumulation curves, based on randomized data, using EstimateS 6.0 (Colwell and Coddington 1994; program available online $)^{2}$ and estimated total richness with

\footnotetext{
${ }^{2}\langle$ http://viceroy.eeb.uconn.edu/EstimateS $\rangle$
} 
SpecRich (Burnham and Overton 1979; program available online $)^{3}$. Since ants are social insects we constructed accumulation curves using presence/absence data, not the number of individuals captured (Longino et al. 2002). We statistically distinguished observed richness in natural and artificial nests with PAST (Hammer et al. 2001; program available online $)^{4}$ and distinguished estimated richness using $t$ tests. PAST compares several diversity indices using observed and randomized data sets such that the number of 1000 simulations where the observed differences in diversity indices between sites is greater than randomized difference determines the level of significance in differences (i.e., the $P$ value) between two sites or nest types.

To investigate differences in ant species composition, namely relative abundance of particular species in artificial vs. natural nests, we developed a randomization model conceptually equivalent to a two-tailed $t$ test using Turbo Pascal version 5 (Supplement). The model first created an array representing actual species occurrences in all natural nests found. Species were then drawn at random from this array to fill an array the size of all artificial nests harvested. Drawings were repeated 1000 times to generate a frequency distribution equivalent to the expected occurrence of each species in artificial nests if this were a random sample of natural nests. The model then compared observed occurrences of each ant species in artificial nests to the frequency distributions to determine if the species was observed significantly more or less often than at random. If observed values for a species fell in the lower $5 \%$ of the distribution, this ant was significantly more common in artificial than in natural nests, and if in the upper $5 \%$ of the distribution, this ant was significantly less common in artificial than in natural nests. We analyzed data for high- and low-shade sites separately.

We also plotted relative abundance of each species in artificial vs. natural nests to graphically demonstrate if particular species were more represented in one nest type. This plot further allowed us to examine if particular ant species were better competitors or better colonizers in high- or low-shade sites (see Savolainen and Vepsaelaeinen 1988, Hölldobler and Wilson 1990, Stanton et al. 2002 for similar characterizations). We included as "competitors" any species that were very abundant ( $>20 \%$ of all nests) in natural nests and overrepresented as compared to their abundance in artificial nests. We included as "colonizers" any species that were very common in artificial nests $(>20 \%$ of total nests) and overrepresented in artificial nests as compared to their abundance in natural nests. Threshold levels of $20 \%$ were assigned a posteriori based on ant relative abundances in nests.

\footnotetext{
${ }^{3}\langle$ http://www.mbr-pwrc.usgs.gov/software/specrich.html $\rangle$

${ }^{4}\langle\mathrm{http}: / /$ folk.uio.no/ohammer/past/index.html $\rangle$
}
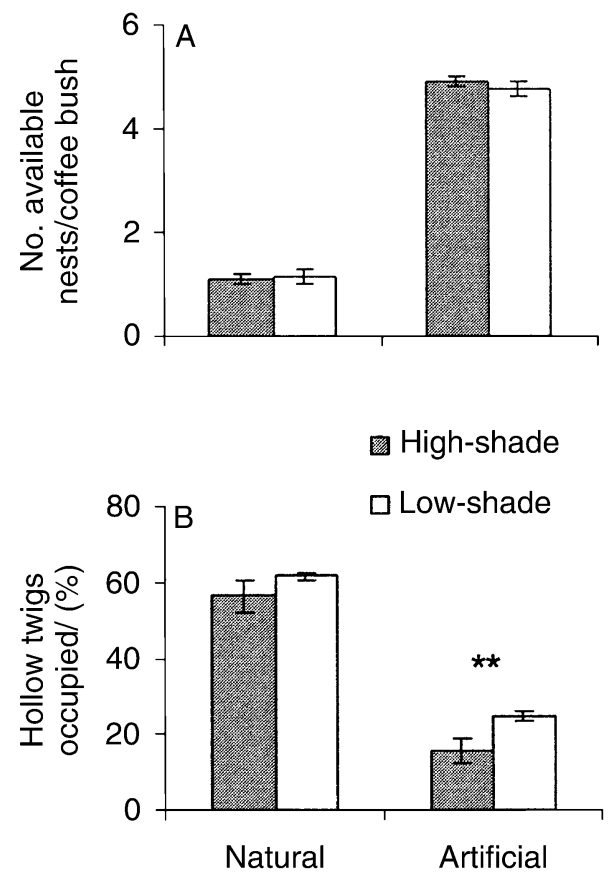

FIG. 1. (A) Nest availability and (B) occupancy in natural coffee twig and artificial bamboo nests collected every two months over three years in two high- and two low-shade coffee sites. Nest availability is shown as mean number of available artificial and natural nests per coffee bush. Mean percentages of occupied nests for artificial nests were standardized on a per-60-day basis. All error bars show \pm SE, and asterisks show significant differences $(P<0.01)$ between neighboring columns.

\section{RESUlts}

Field studies

Natural nest sites in coffee plants were rare with over half of coffee plants in high- (128 of 241, 53\%) and low-shade sites (189 of 359, 53\%) lacking any hollow twigs (Fig. 1A). On average, there was only about one available nest site per plant, and numbers of available nests did not differ between high- and low-shade sites $\left(F_{1,269}=0.013, P=0.91\right.$, Fig. 1A). Ants occupied a majority of natural nests and occupied some artificial nests in both management systems (Fig. 1B). Of available nest sites, a majority were occupied in both the high- $(56.5 \%)$ and low-shade sites (61.7\%) (Fig. 1B) and the proportion of occupied natural nests did not significantly differ between high- and low-shade sites $\left(F_{1,269}=0.962, P=0.328\right)$. We recovered nearly all artificial nests from coffee plants, and numbers of artificial nests per plant did not differ between high- and low-shade sites $\left(F_{1,943}=2.769, P=0.096\right.$, Fig. 1A). In contrast to natural nests, there were nearly $40 \%$ more artificial nests occupied in low- $(41.0 \%)$ than in the high-shade sites $\left(25.8 \% ; F_{1,943}=38.431, P<0.001\right.$, Fig. 1B).

We found a total of 14 ant species occupying natural nests, 9 in high-shade sites, and 12 in the low-shade 
TABLE 1. Ant species found in artificial (bamboo) and natural (coffee twig) nests in high-shade (H) and low-shade (L) coffee sites and in total (T).

\begin{tabular}{|c|c|c|c|c|c|c|c|c|c|}
\hline \multirow[b]{2}{*}{ Species } & \multicolumn{3}{|c|}{ Artificial } & \multicolumn{3}{|c|}{ Natural } & \multicolumn{3}{|c|}{ Abundance } \\
\hline & $\mathrm{H}$ & $\mathrm{L}$ & $\mathrm{T}$ & $\mathrm{H}$ & $\mathrm{L}$ & $\mathrm{T}$ & $\mathrm{H}$ & $\mathrm{L}$ & $\mathrm{T}$ \\
\hline \multicolumn{10}{|l|}{ Dolichoderinae } \\
\hline Azteca instabilis (F. Smith 1862) & 0 & 17 & 17 & 0 & 0 & 0 & NA & $\mathrm{A} \dagger$ & $\mathrm{A} \dagger$ \\
\hline Dolichoderus debilis (Emery 1890) & 1 & 3 & 4 & 2 & 3 & 5 & $\mathrm{~N}$ & $\mathrm{~N}$ & $\mathrm{~N}$ \\
\hline Linepithema sp. 1 & 2 & 0 & 2 & 0 & 0 & 0 & $\mathrm{~A} \dagger$ & NA & $A \dagger$ \\
\hline Tapinoma sp. 1 & 1 & 1 & 2 & 0 & 0 & 0 & $\mathrm{~A} \dagger$ & $\mathrm{A} \dagger$ & $\mathrm{A} \dagger$ \\
\hline Technomyrmex sp. 1 & 47 & 43 & 90 & 0 & 0 & 0 & $\mathrm{~A} \dagger$ & $A \dagger$ & $A \dagger$ \\
\hline \multicolumn{10}{|l|}{ Formicinae } \\
\hline Brachymyrmex heeri (Forel 1874) & 0 & 0 & 0 & 0 & 1 & 1 & NA & $\mathrm{N} \dagger$ & $\mathrm{N} \dagger$ \\
\hline Camponotus abditus (Wheeler 1904) & 18 & 13 & 31 & 24 & 2 & 26 & A & A & $\mathrm{N}$ \\
\hline Camponotus abscisus (Roger 1863) & 28 & 23 & 51 & 2 & 0 & 2 & A & $A \dagger$ & A \\
\hline Camponotus senex textor (Forel 1899) & 1 & 28 & 29 & 0 & 0 & 0 & $\mathrm{~A} \dagger$ & $\mathrm{A} \dagger$ & $A \dagger$ \\
\hline Camponotus striatus (Fr. Smith 1862) & 0 & 1 & 1 & 0 & 0 & 0 & NA & $\mathrm{A} \dagger$ & $A \dagger$ \\
\hline Camponotus senex (Fr. Smith 1858) & 1 & 15 & 16 & 0 & 0 & 0 & $\mathrm{~A} \dagger$ & $A \dagger$ & $A \dagger$ \\
\hline Myrmelachista sp. 1 & 1 & 2 & 3 & 0 & 0 & 0 & $\mathrm{~A} \dagger$ & $\mathrm{A} \dagger$ & $\mathrm{A} \dagger$ \\
\hline \multicolumn{10}{|l|}{ Myrmicinae } \\
\hline Cephalotes atratus (Linnaeus 1758) & 1 & 0 & 1 & 0 & 0 & 0 & $\mathrm{~A} \dagger$ & NA & $\mathrm{A} \dagger$ \\
\hline Crematogaster spp. & 61 & 50 & 111 & 4 & 4 & 8 & A & A & A \\
\hline Nesomyrmex echinatinodis (Forel 1886) & 34 & 219 & 253 & 9 & 53 & 62 & A & A & A \\
\hline Procryptocerus scabriusculus (Forel 1899) & 51 & 48 & 99 & 16 & 14 & 30 & $\mathrm{E}$ & $\mathrm{E}$ & $\mathrm{E}$ \\
\hline Solenopsis sp. 1 & 25 & 5 & 30 & 0 & 1 & 1 & $\mathrm{~A} \dagger$ & $\mathrm{E}$ & A \\
\hline \multicolumn{10}{|l|}{ Poneromorphs } \\
\hline Poneromorph sp. 1 & 4 & 1 & 5 & 0 & 0 & 0 & $\mathrm{~A} \dagger$ & $A \dagger$ & $\mathrm{A} \dagger$ \\
\hline \multicolumn{10}{|l|}{ Pseudomyrmecinae } \\
\hline Pseudomyrmex ejectus (F. Smith 1858) & 5 & 11 & 16 & 15 & 25 & 40 & $\mathrm{~N}$ & $\mathrm{~N}$ & A \\
\hline Pseudomyrmex elongatus (Mayr 1870) & 15 & 32 & 47 & 5 & 0 & 5 & $\mathrm{E}$ & $A \dagger$ & A \\
\hline Pseudomyrmex gracilis (Fabricius 1804) & 16 & 44 & 60 & 0 & 1 & 1 & $\mathrm{~A} \dagger$ & A & A \\
\hline Pseudomyrmex PSW-53 & 3 & 3 & 6 & 0 & 0 & 0 & $\mathrm{~A} \dagger$ & $A \dagger$ & $\mathrm{A} \dagger$ \\
\hline Pseudomyrmex simplex (F. Smith 1877) & 92 & 52 & 144 & 70 & 110 & 180 & $\mathrm{~N}$ & $\mathrm{~N}$ & $\mathrm{~N}$ \\
\hline Pseudomyrmex sp. 1 & 1 & 0 & 1 & 0 & 1 & 1 & $\mathrm{~A} \dagger$ & $\mathrm{N} \dagger$ & $\mathrm{E}$ \\
\hline Pseudomyrmex sp. 2 & 3 & 40 & 43 & 0 & 0 & 0 & $\mathrm{~A} \dagger$ & $A \dagger$ & $A \dagger$ \\
\hline Pseudomyrmex sp. 3 & 0 & 1 & 1 & 0 & 0 & 0 & NA & $\mathrm{A} \dagger$ & $A \dagger$ \\
\hline \multicolumn{10}{|l|}{ Unknown } \\
\hline Formicidae sp. 1 & 1 & 0 & 1 & 0 & 2 & 2 & $\mathrm{~A} \dagger$ & $\mathrm{N} \dagger$ & $\mathrm{N}$ \\
\hline Total species encountered & 23 & 22 & 26 & 9 & 12 & 14 & & & \\
\hline Total number of unique species & 14 & 13 & 13 & 0 & 3 & 1 & & & \\
\hline Total number more abundant & 18 & 17 & 20 & 3 & 6 & 5 & & & \\
\hline
\end{tabular}

Notes: Numbers show how many nests were occupied by each species. Abundance shows which species were discovered significantly more frequently in artificial (A) or natural (N) nests, or were equally abundant (E) according to the randomization model. Daggers show which species were unique to each nest type in each site or overall.

sites, and 26 species in artificial nests, 23 in high- and 22 in low-shade sites (Table 1). The most common ant species in natural nests were Pseudomyrmex simplex F. Smith (180 nests, $49.5 \%$ of nests), Nesomyrmex echinatinodis Forel $(62,17.0 \%)$, Pseudomyrmex ejectus F. Smith (40, 10.9\%), and Procryptocerus scabriusculus Forel $(30,8.2 \%)$. The most common ant species in artificial nests were $N$. echinatinodis $(253,23.8 \%), P$. simplex (144, 13.5\%), Crematogaster spp. (111, $10.4 \%)$, and P. scabriusculus $(99,9.3 \%)$.

There were twice as many ant species captured from artificial than from natural nests both in high- $(P<$ $0.0001)$ and low-shade $(P=0.018)$ sites (Fig. 2A). Furthermore, according to SpecRich, total richness across all artificial nests was estimated to be four times greater than for natural nests in high-shade sites $(t=$ 108.35, df $=413, P<0.0001)$ and estimated to be one and a half times greater in artificial nests in the low-shade sites $(t=55.113$, df $=421, P<0.001$, Fig. $2 \mathrm{~B})$. The number of species occupying artificial and natural nests in both high- and low-shade sites differed (Fig. 2B). The number of species estimated to occupy natural nests in the low-shade sites (15) was nearly $70 \%$ higher than for the high-shade sites (9) $(t=$ 89.229 , df $=222, P<0.001)$. The total number of species estimated to occupy artificial nests in the lowshade sites (26) was nearly $50 \%$ lower than for highshade sites (38.64) $(t=-33.954, \mathrm{df}=491, P<0.001)$.

\section{Species relative abundance}

Ant species abundance greatly differed between artificial and natural nests as many more species were found in a higher proportion of artificial nests than expected given their abundance in natural nests. In 

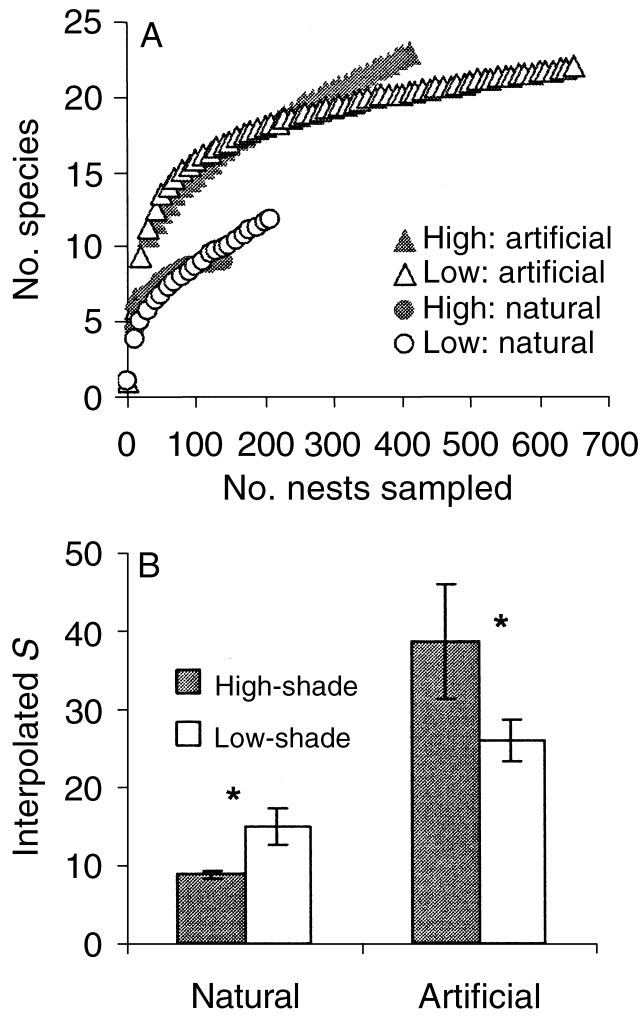

FIG. 2. Ant species richness in natural coffee twig and artificial bamboo nests collected every two months over three years in two high- and two low-shade coffee sites: (A) observed species accumulation curves generated using EstimateS; (B) estimated species richness calculated using SpecRich. Error bars show \pm SE, and asterisks show significant differences $(P<0.05)$ between neighboring columns. Observed and estimated richness values were significantly higher in artificial nests in both high- and low-shade sites.

high-shade sites, 14 species were found in only artificial nests and none were found only in natural nests. In low-shade sites, 13 species were unique to artificial nests and three species were unique to natural nests. Including those species unique to one nest type, there were six times more species found in a higher proportion of artificial nests than in natural nests in highshade sites $\left(\chi^{2}, P=0.00003\right)$ and nearly three times more species that were found in a higher proportion of artificial nests in low-shade sites $\left(\chi^{2}, P<0.0007\right)$. Of the 23 species found in high-shade sites, 18 were more abundant in artificial nests, three were more abundant in natural nests, and two were equally abundant (Table 1). Of the 25 species found in low-shade sites, 17 were more abundant in artificial nests, six were more abundant in natural nests, and two were equally abundant in artificial and natural nests (Table 1).

Of those species that were very abundant in either natural or artificial nests (representing $>20 \%$ of total nests), one species was overrepresented in natural nests and one species was overrepresented in artificial nests (Fig. 3). In the high-shade sites, $P$. simplex was found in $47.6 \%$ of artificial nests and only in $22 \%$ of natural nests. In the low-shade sites, $P$. simplex occurred in $50.7 \%$ of artificial nests and only in $8 \%$ of natural nests. This ant was overrepresented in natural nests, and is thus a good competitor, based on our classification system, both in high- and lowshade sites. In the low-shade sites, $N$. echinatinodis was found in $33.6 \%$ of natural nests and in only $24.4 \%$ of the high-shade sites, and could be classified as a good colonizer in high-shade sites.

\section{DISCUSSION}

We predicted that if nest sites are a limiting resource for arboreal twig-nesting ants especially under influences of habitat modification that (1) ants would occupy most natural and artificial nests sites and (2) a higher proportion of natural and artificial nests would be occupied in more intensively managed (low-shade) sites. A majority $(>55 \%)$ of naturally occurring nests and some $(>15 \%)$ artificial nests were occupied by ants. Furthermore, although proportions of occupied natural nests did not differ between management types, a significantly higher proportion of artificial nests were occupied in low- than in high-shade sites. Thus arboreal twig-nesting ants are generally not severely nest-site limited in coffee agroecosystems, but nest-site limitation may increase under more intensive management (Torres 1984, Herbers 1986, Byrne 1994, Perfecto and Vandermeer 1994, Andresen 2003). We also expected that increasing nest availability would increase ant diversity so that (1) ant richness would be greater in artificial nests and (2) ant species composition would differ between nest types where more species occur in a higher proportion of artificial nests than natural nests.

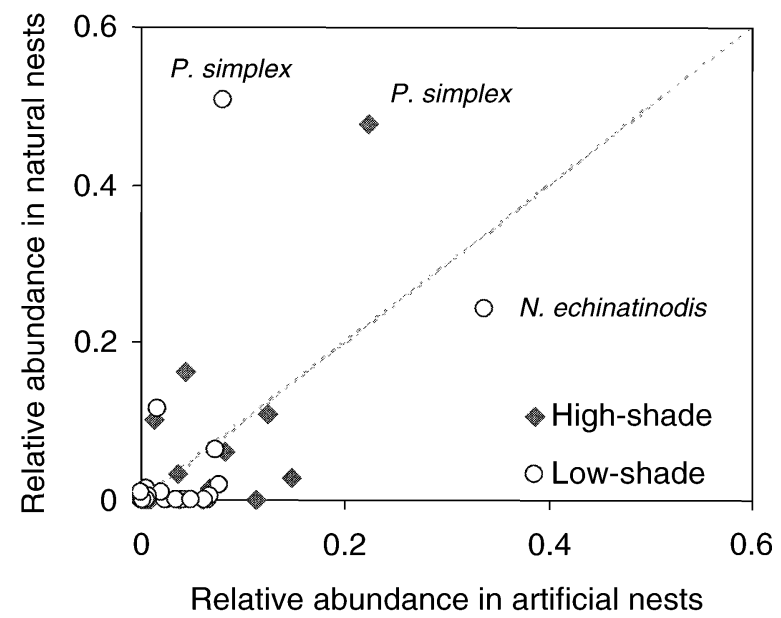

FIG. 3. Relative abundance (proportion of total nests occupied) of each ant species in artificial bamboo nests and in natural hollow coffee twig nests in both high- and low-shade coffee agroecosystems. The $45^{\circ}$ angle line shows equal abundance in each type of nest. Pseudomyrmex simplex was relatively more abundant in natural nests in both high- and lowshade sites, whereas Nesomyrmex echinatinodis was relatively more abundant in artificial nests only in the low-shade sites. 
Both observed and estimated ant richness was significantly greater in artificial nests than in natural nests, and significantly more ant species were only or more frequently found in artificial nests.

Both ant species richness and abundance of the majority of ant species were greater in artificial than in natural nests, perhaps resulting from nest-site competition, a competition colonization trade-off, or opportunistic artificial nest use. Most of the ant species found only in artificial nests, such as Pseudomyrmex spp. and Nesomyrmex spp. are typical twig-dwelling ants (Fonseca 1999, Foitzik and Heinze 1998, Ward 1999, Bizerril and Vieria 2002). These species may have been competitively excluded by Pseudomyrmex simplex, which occupied nearly half of all of natural nests in both high- and low-shade sites or by other twig-dwelling ants that are generally more abundant in natural nests. Artificial nests remained in the field for approximately two months each, whereas natural nests may have been established much before the two-month period. It is possible that competitive exclusion may be occurring such that most ants occupying new nesting sites (artificial nests) are better colonizers whereas the ants more common in natural nests are better competitors (Tilman 1994, Stanton et al. 2002). For example, $N$. echinatinodis was overrepresented in artificial nests in the high-shade sites and could be categorized as a good colonizer. Based on natural history, many species encountered only in artificial nests were not expected to colonize twig nests. Specifically, we found queens and workers of dominant carton-building ants Azteca instabilis (F. Smith) and the nest-weaving Camponotus senex textor (F. Smith) in artificial nests (Majer 1972, Room 1975, Leston 1978). Although the persistence of these colonies was not examined, these ants may opportunistically use artificial nests in addition to their carton nests. Specifically, those ants unexpectedly using artificial nests normally nest in the shade-tree layer, and specific ants dominating in the shade and coffee layers are known to differ (Armbrecht 2003).

Higher ant richness in artificial nests and more frequent use of artificial nests in the low-shade sites may be due to nest-site selectivity, colony expansion, or nest relocation. Although we tried to minimize differences between natural and artificial nests by placing bamboo directly on and flush with coffee twigs, and by varying the size of bamboo twigs to mimic natural nests, bamboo twigs may have been easier to colonize or otherwise of better quality than natural coffee twig nests to either more species (in both management types) or to greater quantities of ants (in the low-shade site) enhancing not only formation of new colonies but also nest relocation. Certainly, some ants show high levels of nest-site selectivity (e.g., Djieto-Lordon and Dejean 1999, Mallon et al. 2001). Evidence exists, however, showing that some twig-nesting ants inhabit a wide range of twig types (Byrne 1994) or that ants do not prefer particular species of twigs but rather an inherent diversity of sites in one area (Armbrecht et al. 2004). Many ant species are polydomous, occupying several nest sites per colony (Hölldobler and Wilson 1994) and polydomy may result from nest-size limitation (Byrne 1994). Especially in low-shade sites, colony expansion from neighboring shade or coffee trees may have been facilitated by high coffee planting densities where plants touch increasing ant movement. Regardless of which factor or factors are ultimately responsible for the changes in ant richness and species composition between natural and artificial nets, these results provide evidence that nest-site limitation (either in terms of number or quality of nests) may restrict ant diversity and may be one mechanism responsible for declines in ant diversity with coffee intensification.

Although nesting-site resources may strongly limit ant richness or colony numbers, ants also may be limited by dispersal or recruits. Recruitment limitation may be one important factor determining the relative species abundance and overall diversity of communities ranging from tropical forests to coral reefs (e.g., Hubbell 2001). At least one study has found that ant populations may be limited by number of overall recruits. Cole and Wiernasz (2002) documented that populations of the harvester ant (Pogonomyrmex occidentalis Cresson) were spatially limited such that near leks nesting sites were limited, but far from leks, the species experienced recruitment limitation. Although this particular case focuses on population density of one species, it may shed light on community level processes relevant to this study. In this study, estimated total richness was higher for artificial nests than for natural nests in both high- and low-shade sites, indicating that the total number of available nests may limit the number of species in coffee agroecosystems. However, in the low-shade sites, estimated richness in natural nests was greater and in artificial nests was lower than in high-shade sites such that richness in artificial nests increased by $>75 \%$ in high-shade sites, but only by $42 \%$ in low-shade sites. If ant species are spatially restricted as to where recruits (alates) are sent, this may indicate that fewer total species are located within the low-shade habitats or can disperse the distance required to colonize these habitats. Therefore, overall ant species richness in intensive coffee agroecosystems may be limited by the total number of recruits, so that increasing total nest availability in high-shade sites may better maintain ant diversity.

Determining the causal factors for why ant diversity is higher in artificial nests needs to be elucidated by further work on arboreal twig-nesting ants. Staged interactions between particular species of ants may help determine if competitive interactions are a driving force. Repeated and more frequent sampling of the same nests over time could explain if a competition-colonization trade-off is at play as one would predict if the nest occupants of a given nest change over time. To examine if nest relocation or colony expansion are important in 
artificial nest colonization, artificial nests could be placed on isolated coffee plants from which ants (and all ant nests) are experimentally removed. On such plants, only alate ants would be able to colonize artificial nests because nest expansion or relocation will most likely occur by walking rather than flying. Finally, to address issues of nest quality, several types of nests of standard size, material, and age could be offered as potential nest sites (see Armbrecht et al. 2004).

Showing that diversity or abundance of arboreal twig-nesting ants increased in artificial nests has important implications for using ants as biological control agents in coffee agroecosystems. Ant diversity was higher in artificial nests, and adding artificial nests will also increase the number of ant colonies or the number of workers per colony. Ants are important predators in many tropical agroecosystems (Way and Khoo 1992, Perfecto and Castiñeiras 1998), and ecosystem services, such as pest control, may be enhanced with higher predator abundance and diversity (e.g., Myers 1996, Balvanera et al. 2001). Perhaps due to nest-site limitation in agroecosystems, successful biological control strategies often include use of artificial nests to transport and augment ant populations in systems where ants are considered useful. In China, ants have been used for centuries to control citrus pests, and management practices include using bamboo poles (serving as nests and bridges between trees) to augment ant abundance and distributions (Yang 1982, Needham 1986, Huang and Yang 1987). Palm fronds are used as artificial nests for Dolichoderus thoracicus F. Smith, a control agent in cacao plantations, suggesting these ants are also nest-limited (Khoo and Chung 1989, Way and Khoo 1992). In Cuba, colonies of Pheidole megacephala Fabricius are moved after they colonize traps (bundles of banana leaves) and are transported to other low ant density areas (Castiñeiras 1985).

In summary, ants in coffee agroecosystems are more nest-site limited in more intensively managed sites. Richness of arboreal twig-nesting ants was higher in the artificial nests, and although ants seem to be somewhat recruitment limited, especially in the low-shade sites, using artificial nests in coffee plantations may be one way to augment and maintain ant diversity and density with important implications for biological control strategies.

\section{ACKNOWLEDGMENTS}

J. Maldonado, B. E. Chilel, J. A. García Ballinas, G. López, A. Méndez Mendizabal, A. Hammond, J. C. Méndez López, F. B Camposeco Silvestre, J. L Cabrera Santos, and P. Bichier helped with data collection in the field. The Peters and Eddelman families and the ISMAM Cooperative graciously allowed us to work on their farms. G. Ibarra-Núñez from El Colegio de la Frontera Sur in Tapachula provided logistical support. R. Burnham, I. Armbrecht, I. Perfecto, B. Rathcke, and J. Vandermeer provided comments on the manuscript. G. Estabrook helped with development of the model. Ant identification was aided by I. Armbrecht, W. McKay, and P. Ward. This research was supported by NSF grant number DEB-
9981526 to I. Perfecto, the Helen Olsen Brower Fellowship in Environmental Science, Sokol International Fellowship, Block Grant, Latin American and Caribbean Studies Department, and Rackham Regent's Fellowship of the University of Michigan, and an NSF Graduate Research Fellowship to S. Philpott.

\section{Literature Cited}

Andresen, D. 2003. The effects of the intensification of coffee production on arboreal ants and their nesting sites. Master's Thesis. University of Michigan, Ann Arbor, Michigan, USA. Armbrecht, I. 2003. Diversity and function of leaf litter ants in Colombian coffee agroecosystems. Ph.D. Dissertation. University of Michigan, Ann Arbor, Michigan, USA.

Armbrecht, I., and I. Perfecto. 2003. Litter-dwelling ant species richness and predation potential within a forest fragment and neighboring coffee plantations of contrasting habitat quality in Mexico. Agriculture, Ecosystems and Environment 97:107-115.

Armbrecht, I., I. Perfecto, and J. Vandermeer. 2004. Enigmatic biodiversity correlations: ant diversity responds to diverse resources. Science 304:284-286.

Balvanera, P., G. C. Daily, P. R. Ehrlich, T. H. Ricketts, S. A. Bailey, S. Kark, C. Kremen, and H. Pereira. 2001. Conserving biodiversity and ecosystem services. Science 291: 2047.

Bizerril, M. X. A., and E. M. Vieira. 2002. Azteca ants as antiherbivore agents of Tococa formicaria (Melastomataceae) in Brazilian Cerrado. Studies on Neotropical Fauna and Environment 37:145-149.

Brian, M. V. 1952. Interaction between ant colonies at an artificial nest site. Entomologist's Monthly Magazine 88: $84-88$.

Burnham, K. P., and W. S. Overton. 1979. Robust estimation of population size when capture probabilities vary among animals. Ecology 60:927-936.

Byrne, M. M. 1994. Ecology of twig-dwelling ants in a wet lowland tropical forest. Biotropica 26:61-72.

Carroll, C. R. 1979. Comparative study of 2 ant faunasstem-nesting ant communities of Liberia, West-Africa and Costa-Rica, Central-America. American Naturalist 113: 551-561.

Castiñeiras, A. 1985. Evaluation of traps for colonies of Pheidole megacephala (Hymenoptera: Formicidae). Ciencia y Técnica en la Agricultura-Protección de Plantas (Havana, Cuba) 8:99-106.

Cerda, X., and J. Retana. 1998. Interference interactions and nest usurpation between two subordinate ant species. Oecologia 113:577-583.

Cole, B., and D. Wiernasz. 2002. Recruitment limitation and population density in the harvester ant, Pogonomyrmex occidentalis. Ecology 83:1433-1442.

Colwell, R. K., and J. A. Coddington. 1994. Estimating terrestrial biodiversity through extrapolation. Philosophical Transactions of the Royal Society of London Series B Biological Sciences 345:101-118.

Davidson, D. W. 1997. The role of resource imbalances in the evolutionary ecology of tropical arboreal ants. Biological Journal of the Linnaean Society 61:153-181.

Davidson, D. W., S. Cook, R. Snelling, and T. Chua. 2003. Explaining the abundance of ants in lowland tropical rainforest canopies. Science 300:969-972.

Davidson, D. W., R. R. Snelling, and J. T. Longino. 1989. Competition among ants for myrmechophytes and the significance of plant trichomes. Biotropica 21:64-73.

Djieto-Lordon, C., and A. Dejean. 1999. Tropical arboreal ant mosaics: innate attraction and imprinting determine nest site selection in dominant ants. Behavioral Ecology and Sociobiology 45:219-225.

Fernandez-Escudero, I., and A. Tinaut. 1999. Factors determining nest distribution in the high-mountain ant Profor- 
mica longiseta (Hymenoptera: Formicidae). Ethology Ecology and Evolution 11:325-338.

Foitzik, S., and J. Heinze. 1998. Nest site limitation and colony takeover in the ant Leptothorax nylanderi. Behavioral Ecology 9:367-375.

Fonseca, C. R. 1999. Amazonian ant-plant interactions and the nesting space limitation hypothesis. Journal of Tropical Ecology 15:807-825.

Hammer, Ø., D. Harper, and P. Ryan. 2001. PAST: paleontological statistics software package for education and data analysis. Palaeontologia Electronica 4:1-9.

Hasegawa, E. 1993. Nest defense and early production of the major workers in the dimorphic ant Colobopsis nipponicus (Wheeler) (Hymenoptera: Formicidae). Behavioral Ecology and Sociobiology 33:73-77.

Herbers, J. M. 1986. Nest site limitation and facultative polygyny in the ant Leptothorax longispinosus. Behavioral Ecology and Sociobiology 19:115-122.

Hölldobler, B., and E. Wilson. 1990. The ants. Harvard University Press, Cambridge, Massachusetts, USA.

Huang, H., and P. Yang. 1987. The ancient cultured citrus ant. BioScience 37:665-671.

Hubbell, S. 2001. The unified theory of biodiversity and biogeography. Princeton University Press, Princeton, New Jersey, USA.

Kaspari, M. 1996. Testing resource-based models of patchiness in four Neotropical litter ant assemblages. Oikos 76: 443-454.

Khoo, K., and G. Chung. 1989. Use of the black cocoa ant to control mirid damage in cocoa. Planter (Kuala Lumpur) 65:370-383.

Leston, D. 1978. Neotropical ant mosaic. Annals of the Entomological Society of America 71:649-653.

Longino, J. T., J. Coddington, and R. K. Colwell. 2002. The ant fauna of a tropical rain forest: estimating species richness three different ways. Ecology 83:689-702.

Majer, J. D. 1972. Ant mosaic in Ghana cocoa farms. Bulletin of Entomological Research 62:151-160.

Mallon, E., S. Pratt, and N. Franks. 2001. Individual and collective decision-making during nest site selection by the ant Leptothorax albipennis. Behavioral Ecology and Sociobiology 50:352-359.

Mas, A. H., and T. V. Dietsch. 2003. An index of management intensity for coffee agroecosystems to evaluate butterfly species richness. Ecological Applications 13:1491-1501.

Moguel, P., and V. M. Toledo. 1999. Biodiversity conservation in traditional coffee systems of Mexico. Conservation Biology 13:11-21.

Myers, N. 1996. Environmental services of biodiversity. Proceedings of the National Academy of Sciences (USA) 93 : 2764-2769.

Needham, J. 1986. Science and civilization in China. Biology and biological technology. Cambridge University Press, Cambridge, UK.

Nestel, D., and F. Dickschen. 1990. The foraging kinetics of ground ant communities in different Mexican coffee agroecosystems. Oecologia 84:58-63.

Perfecto, I., and A. Castiñeiras. 1998. Deployment of the predaceous ants and their conservation in agroecosystems. Pages 269-289 in P. Barbosa, editor. Conservation biological control. Academic Press, San, Diego, California, USA

Perfecto, I., A. Mas, T. Dietsch, and J. Vandermeer. 2003. Conservation of biodiversity in coffee agroecosystems: a tri-taxa comparison in southern Mexico. Biodiversity and Conservation 12:1239-1252.

Perfecto, I., R. A. Rice, R. Greenberg, and M. E. VanderVoort. 1996. Shade coffee: a disappearing refuge for biodiversity. BioScience 46:598-608.

Perfecto, I., and R. Snelling. 1995. Biodiversity and the transformation of a tropical agroecosystem: ants in coffee plantations. Ecological Applications 5:1084-1097.

Perfecto, I., and J. Vandermeer. 1994. Understanding biodiversity loss in agroecosystems: reduction of ant diversity resulting from transformation of the coffee ecosystem in Costa Rica. Entomology 2:7-13.

Perfecto, I., and J. Vandermeer. 2002. Quality of agroecological matrix in a tropical montane landscape: ants in coffee plantations in southern Mexico. Conservation Biology 16:174-182.

Perfecto, I., J. Vandermeer, P. Hanson, and V. Cartin. 1997. Arthropod biodiversity loss and the transformation of a tropical agro-ecosystem. Biodiversity and Conservation 6: 935-945.

Ribas, C. R., and J. H. Schoereder. 2002. Are all ant mosaics caused by competition? Oecologia 131:606-611.

Roberts, D. L., R. J. Cooper, and L. J. Petit. 2000. Use of premontane moist forest and shade coffee agroecosystems by army ants in western Panama. Conservation Biology 14: 192-199.

Room, P. 1975. Relative distributions of ant species in cocoa plantations in Papua New Guinea. Journal of Applied Ecology 12:47-62.

Savolainen, R., and K. Vepsaelaeinen. 1988. A competition hierarchy among boreal ants: impact on resource partitioning and community structure. Oikos 51:135-155.

Solano, P., S. Durou, B. Corbara, A. Quilichini, P. Cerdan, M. Belin-Depoux, J. Delabie, and A. Dejean. 2003. Myrmecophytes of the understory of French Guianian rainforests: their distribution and their associated ants. Sociobiology 41:605-614.

Stanton, M., T. Palmer, and T. Young. 2002. Competitioncolonization trade-offs in a guild of African Acacia-ants. Ecological Monographs 72:347-363.

Tilman, D. 1994. Competition and biodiversity in spatially structured habitats. Ecology 75:2-16.

Torres, J. A. 1984. Niches and coexistence of ant communities in Puerto Rico: repeated patterns. Biotropica 16:284295.

Vasconcelos, H. 1993. Ant colonization of Maieta guianensis seedlings, an Amazon ant-plant. Oecologia 95:439-443.

Ward, P. S. 1999. Systematics, biogeography and host plant associations of the Pseudomyrmex viduus group (Hymenoptera: Formicidae), Triplaris- and Tachigali-inhabiting ants. Zoological Journal of the Linnaean Society 126:451540 .

Way, M. J., and B. Bolton. 1997. Competition between ants for coconut palm nesting sites. Journal of Natural History 31:439-455.

Way, M. J., and K. C. Khoo. 1992. Role of ants in pest management. Annual Review of Entomology 37:479-503.

Yamaguchi, T. 1992. Interspecific interference for nest sites between Leptothorax congruus and Monomorium intrudens. Insectes Sociaux 39:117-127.

Yang, P. 1982. Biology of the yellow citrus ant, Oecophylla smaragdina and its utilization against citrus insect pests. Acta Scientiarum Naturalium Universitatis Sunyatseni 3: $102-105$.

\section{SUPPLEMENT}

The randomization model code for Turbo Pascal Version 5 used to distinguish relative species abundance of arboreal ants in natural or artifical nests in cofffee farms in Chiapas, Mexico, is available in ESA's Electronic Data Archive: Ecological Archives A015-041-S1. 